\title{
Application and Exploration of BOPPPS Model in Oral Chinese Teaching as a Foreign Language
}

\author{
Hongmei $\mathrm{Cui}^{1}$ \\ ${ }^{1}$ School of International Education, Ningxia Medical University, China \\ Correspondence: Hongmei Cui, School of International Education, Ningxia Medical University, Yinchuan, \\ Ningxia Hui Autonomous Region, 750004, China.
}

Received: August 16, 2019

Accepted: September 19, 2019

Online Published: November 29, 2019

doi:10.5539/ies.v12n12p123

URL: https://doi.org/10.5539/ies.v12n12p123

\begin{abstract}
In recent years, with the continuous development of the society, the boom of global Chinese learning has flourished. The teaching and research of Chinese as a foreign language has received much attention. In order to explore the effective teaching methods in oral Chinese, to stimulate foreign students' love of learning Chinese, and to increase their interest and motivation in learning Chinese, a new teaching model-BOPPPS teaching model emerges and is widely welcomed by the students. The author explores how to apply the BOPPPS model in teaching of oral Chinese as a foreign language, providing a new teaching method in oral Chinese teaching. The study finds that the BOPPPS model can improve the efficiency and effectiveness of the oral Chinese teaching, mobilize international students' enthusiasm for learning Chinese and improve their academic performance, make teachers more clear about the teaching purpose and requirements, and help the students be more clear about the learning goals.
\end{abstract}

Keywords: BOPPPS teaching model, Chinese as a foreign language, oral Chinese teaching, teaching effect

\section{Introduction}

With the rapid development of the society, the global studying of Chinese language is booming. The research of Chinese teaching has received much attention. Both China and many foreign countries have attached great importance to Chinese language teaching and research. Statistics from the Ministry of Education show that a total of 492.000 international students were studying in colleges and universities in China in 2018 (Ministry of Education, 2019).

Oral Chinese is the first major problem faced by international students after coming to China. It is a common communication problem for international students. How to enable the international students to master basic Chinese communication methods in a short period of time and improve the level of Chinese communication has become the top priority of oral Chinese teaching. The method and strategy of oral Chinese teaching as a foreign language is therefore particularly important. However, in the actual oral teaching process, due to the teacher's single teaching skills, student's insufficient participation and other factors, the students have always been in a passive learning state for a long time. The student's interest and enthusiasm for learning Chinese gradually begins to decrease, their positiveness is also weakened, and the oral Chinese proficiency is getting more and more difficult to be improved.

In view of the ineffectiveness of oral Chinese teaching and the international students' poor oral Chinese expression, many teachers have tried various teaching reforms, but the teaching effect is also not good. Based on the communicative approach and the student-centered basic teaching concept, BOPPPS model adopts a modular decomposition method to cut the teaching process into multiple teaching units of 5 to 15 minutes (Wang \& $\mathrm{Li}$, 2018). The core of the model is to achieve the teaching goal. The model constructs six stages including bridge-in, objective, pre-assessment, participatory learning, post-assessment and summary. These six stages form a systematic and complete teaching process, providing specific operational steps. The model has strong operability. It is an effective tool to systematically guide the curriculum design (Cao \& Yin, 2016).

\section{Method}

\subsection{Research Questions}

a) What are the effects of the BOPPPS model in oral Chinese teaching as a foreign language? 
b) How to apply the BOPPPS model to oral Chinese teaching as a foreign language?

\subsection{Research Objects}

The research objects are 2 classes of sophomore international students from one university in Ningxia Hui Autonomous Region.

\subsection{Research Method}

This paper uses the BOPPPS model to implement teaching practice in the teaching process of "Conversational Chinese 301" (hereinafter referred to as "301"). The teaching effect of BOPPPS model is compared and analyzed through the combination of teaching experiment and interview. The experiment time is for half a year.

\section{The Construction of BOPPPS Model in Oral Chinese Teaching}

\subsection{BOPPPS Teaching Model and Its Connotation}

BOPPPS is a closed-loop feedback model of teaching interaction and reflection (Zhang \& Zhu, 2016). It is a powerful means of interaction between teachers and students, students and students, which can stimulate students' interest in learning. It provides a practical and feasible method for the reform of teaching design. The BOPPPS teaching model is divided into six modules, to achieve the teaching objectives. It focuses on students' participation and feedback, giving full play to students' initiativeness, following a student-centered, goal-oriented teaching philosophy, emphasizing on teaching interaction and reflection, and guiding students to learn independently. The model can also help teachers to decompose and analyze the teaching process (Chen, Zhang \& Wang, 2015), so as to design teaching content more effectively and improve the teaching quality.

\subsubsection{Bridge-In}

A good start is half of the success (Liu, Zhang \& Yang, 2015). A fascinating introduction will take much fun to the course. As the beginning of a lesson, the purpose of setting up the introduction is to attract the students' attention much better, to guide the students to generate strong interest in learning and motivation, and further to urge them to pay attention to the core teaching content that will be carried out. At this stage, the teacher needs to explain the importance of the course will be studied, by telling a story, current events or unusual facts closely related to the core teaching content. The teacher can also organically link the new content with the students' existing knowledge foundations by retelling the content the students has learned in last class, to propose questions related to the teaching theme and guide students to smoothly enter the core teaching content.

\subsubsection{Objective}

This step is to establish the learning objectives of the class and the expected results. The teacher succinctly clarifies the purpose of the study, conveys the teaching objectives, especially the key knowledge and learning value of the course, and clearly informs the students what they can understand or will learn to do through this lesson, so that the students can clearly grasp the direction of learning. Clear and appropriate learning objectives should be determined based on three aspects of cognition, emotion and skill (Niu \& Lou, 2017). The learning objectives have guiding functions, control functions, incentive functions, and evaluation functions. It is both the starting point and the foothold of the course learning requirements. The realization of the goal of course is not only the focus of the teacher's attention, but also the priority of the student's learning. Therefore, in the process of practice, it is necessary to clearly state who is the object, what will be learned, under what condition and how well the effect. Obviously, clear teaching objectives help teachers better to design the corresponding teaching process and improve teaching methods in combination with student characteristics.

\subsubsection{Pre-Assessment}

Pre-assessment is an important prerequisite for effective teaching activities. The purpose of it is to master the students' knowledge reserve, preparation, learning ability and interest, helping teachers set the teaching rhythm. Teachers can timely adjust the teaching methods and ideas according to the results of the pre-assessment, and to improve the depth and progress of the teaching content. For students, the pre-assessment helps them to review the leading knowledge and pave the way for the content to be learned, so as to enter a good learning state as soon as possible. The pre-assessment should be set according to the students' ability, teaching content and teaching objectives. The question styles can be selected questions, fill in the blanks, yes and no questions, questionnaires, preview achievements and experience, and so on.

\subsubsection{Participatory Learning}

Participatory learning refers to the process of adopting active learning strategies to enable students to actively participate in learning to achieve teaching goals. Participatory learning is the main body of teaching. It emphasizes 
on student-centered participatory learning, highlights the initiativeness of the students, stimulates students' interest in learning and enthusiasm, and activates the classroom atmosphere. The learning pyramid studied by the National Training Laboratory in the United States visually shows the effects of using different learning methods, including active learning and passive learning. Passive learning includes listening, reading, audio-visual, demonstration, etc. Active learning includes discussion, practice, teaching others or applying immediately. The effect of passive learning is generally less than $30 \%$, while that of active learning is generally above $50 \%$ (Yan, Chen, \& Wang, 2016). It can be seen that the effect of participatory active learning is better than that of passive learning. Only participatory active learning enables students to achieve the desired learning goals, and the learning is much deeper and more sustainable. As the core of BOPPPS model, participatory learning has strong adaptability and operability.

Participatory learning emphasizes on the important role of students, learning and interaction in teaching. Teachers can create problem situations according to teaching objectives and teaching content. Through reasonable doubts and guidance, students can understand teaching objectives and tasks, and think deeper about the problems. Targeted teaching tasks can be arranged for students to think. The teacher can use variety of teaching strategies such as flip classroom, system teaching, project teaching, problem-driven, group discussion, student presentation, situation method, teacher and student role exchange, inquiry, collaborative method, asymptotic method and progressive method (Wang \& Tian, 2018), to make the classroom interesting, open, shared, practical and innovative. Students will summarize, evaluate, and feedback during the entire teaching process to form an interactive circumstance. After the group discussion, the students need to summarize. The group representatives need to report the discussion results. Teachers should track the students' participation and learning in a timely manner and guide the discussion process. Participatory learning enables students to acquire new knowledge through self-experience, learning, and inquiry. The higher the student's participation, the deeper the knowledge they acquire.

\subsubsection{Post-Assessment}

Post-assessment is to test how well the students achieve teaching goals. The purpose is to understand the students' learning situation in a targeted manner and to make sure the mastery about the students' knowledge points. Based on the evaluation results, teachers can carry out teaching reflection, promote teaching design, improve teaching quality, and help students assess learning status and objectively summarize learning gains. Different post-assessment methods are usually used for different course contents. For theoretical knowledge, questions such as ask and answer, multiple choice questions, and judgment questions can be used. For the application of analytical content, students can connect theory with reality and create situations for analysis. For the operation of demonstration content, students can describe specific operation steps and conditions. For key knowledge points, students can summarize and conclude. For error-prone knowledge points, teachers can use the form of yes and no questions to let students deepen their impressions and avoid mistakes occur again. In short, the post-assessment should establish a flexible and diversified evaluation system to make a truly meaningful evaluation of the learning effect.

\subsubsection{Summary}

This step is designed to help students organize and review what they have learned to further strengthen their learning goals. Summarizing plays the role of inheriting the past and the future. It is not only a summary of the content of this lecture, but also an opportunity for teachers and students to reflect, and also an introduction to the content of the next lecture (Cao \& Yin, 2016). The summary can be completed by the teacher. The teacher helps the students to summarize the content of the teaching, pointing out the key knowledge points and difficulties. Combined with the learning points, the teacher can inform the students the contents and requirements of next class. The summary can also be completed by the students. The students be guided to reflect on what they have learned through simple summarization about the knowledge points or skill points, and what are the deficiencies to facilitate their after-school review. The teacher can further enhance the teaching effect by summarizing and letting students express their knowledge, gains and experiences.

Actually, the solidification of classroom teaching design is not conducive to teaching innovation. Achieving the teaching goal and improving the teaching effect is the purpose of the BOPPPS model (Wang, Zhou, \& Peng, 2016). Practical teaching should be used flexibly, and the elements in the model can be adjusted according to the teaching objectives and teaching content to avoid the classroom teaching design formalization (Niu \& Lou, 2017).

\subsection{Application of BOPPPS Model in Oral Chinese Teaching}

Educational psychology research shows that students' classroom learning focus can last up to 10-15 minutes (Mu $\& \mathrm{Li}, 2015)$. Based on the design of BOPPPS model, the researcher flexibly use various forms of teaching methods in 40 minutes classroom teaching and organize the students to participate class performance actively around the 
communication knowledge points, to promote the "classroom teaching" change to "classroom learning".

\subsubsection{Emphasize on the Necessity of the Preview Section}

One of the goals of oral Chinese teaching is to help students be proficient in what they have learned and use the knowledge in daily communication. Good preview effects can help students understand the learning content in advance and actively participate in classroom learning. The BOPPPS model shifts the focus of learning to the students, so the preview section is especially important. In the actual teaching process, it is found that the international students do not pay much attention to the preview of oral Chinese courses, and they will appear to be somewhat blunt when they enter the course directly. Therefore, teachers can provide preview ideas and resources, such as websites, videos, background knowledge, etc., to inform students what to know and to check the preview effect in time. For example, before the "Mid-Autumn Festival" lesson is taught, the teacher can require the students to watch various small videos about the Mid-Autumn Festival, search the origin, celebration, and meaning of the Mid-Autumn Festival, and submit a preview report. The teacher can also use the pre-class questions, quizzes and other methods to examine the preview effect, and adjust the teaching ideas in time, further to provide students with the most suitable teaching content.

\subsubsection{Enhance the Fun of the Introduction Section}

Oral Chinese teaching is one of the important courses to help students improve their communicative skills quickly. How to improve students' interest in oral Chinese learning will directly affect the improvement of students' Chinese proficiency. The traditional oral Chinese teaching basically enters a theme quickly. The BOPPPS model pays more attention to the introduction of the teaching. It takes a few minutes to attract students' attention by using interesting topics or short videos in life to bring students into the subject of the curriculum. For example, in the lesson of teaching "Do not smoke" in the "301", the course begins with a video about smoking is harmful to health, which draws forth the content to be learned, attracts the attention of the students, stimulates their interest in learning, and smoothly introduces the course into the next step.

\subsubsection{Clarify the Importance of the Teaching Objectives}

Although the theme of the "301" is clear, but there are many knowledge points. A series of lessons may cover a number of content points, which will bring some confusion for the international students to master the key content of the lesson. In the process of learning, students should pay great attention to learn new knowledge. There is little time for them to consider what is to be mastered and what is to be basically understood. As a result, although they have learned a lot of knowledge, they are rather confused. Over time, they will ignore the important knowledge points and reduce the learning efficiency. Therefore, it is very important to clarify the learning objectives. And the objectives should be detailed, to help students easily grasp the key points.

\subsubsection{Permeate the Natural Character of the Test}

Oral Chinese language is a persevering study that gradually improves language proficiency through continuous reading, speaking, communication and practice. In the "301" classroom test section, the teacher can test the student's learning effect by asking questions, recognizing pictures, guessing words, sentence solitaire, and classroom quizzes etc. For example, when teaching the weather, the teacher can display a series of pictures about the weather, ask the students to quickly tell what the weather is, to test the student's mastery by observing their reaction. When teaching the position words, the teacher can ask the students to work together, one person performs and the others guess. Under the relaxed and natural environment, the teacher can easily get whether the students have mastered about the key content, further to enhance the teaching improvement.

\subsubsection{Guide the Students to Participate Actively}

The core of the BOPPPS model is the participatory learning of teachers and students, which is essential for learning the key content. In the process of learning, the student is the subject and the teacher is the leader. By designing classroom activities, such as group discussions, case studies, role-playing, etc., teachers can make the students positively participate in classroom activities. Students can explore the problems through discussion, exchange of opinions, etc., and solve problems under the guidance of the teachers, which can not only improve the students' learning enthusiasm, but also foster their divergent thinking. In "301", different participatory learning methods are used according to different topics. For example, when learning "I want to buy a sweater", the students are divided into several groups, setting up the scene, playing the salesperson and the customer, conducting trading exchanges, and mastering new knowledge points in practice. When learning "Do not smoke", the students are asked to discuss the harm of smoking by watching videos and the teacher just instruct whether the students' expression is accurate or not, to help the students strengthen their memory. 


\subsubsection{Focus on the Necessity of Examining}

In the later stage of the classroom teaching, the teacher can understand the students' mastery of knowledge through simple questions and answers, to detect whether the students have achieved the desired goals. Through the examining of the students, the teacher can analyze whether the teaching is effective in this course, and adjust the teaching content in time, further to reflect and optimize the teaching strategies.

\subsubsection{Emphasize on the Critical Characteristic of the Summary}

It is very important to summarize and conclude, which plays the role of linking up and down. The evaluation and feedback in this link is the central step (Shen, Guo, \& Zhu, 2017). By combining the strengths and shortcomings in the teaching process, the teachers can accumulate experience, adjust teaching links, improve teaching quality, and sublimate teaching effects. Through the teacher's summary, the students will deepen their understanding and master new knowledge.

\section{Result}

Since the BOPPPS teaching model has been applied in the oral Chinese teaching for international students, it has greatly improved the oral Chinese teaching and obviously promotes Chinese teaching effects at different levels.

\subsection{The BOPPPS Model Can Improve the Efficiency and Affect the Oral Chinese Teaching}

After a half-year teaching experiment, the author conducted an anonymous questionnaire survey. A total of 56 questionnaires are sent out and 56 are returned. The following results are drawn. In the preferred teaching model, $90 \%$ of the students like the BOPPPS model. Only 6 students like the traditional teaching model. In the class focus time, the BOPPPS model can always attract students' attention for 40 minutes, while the traditional teaching method can only make students focus on learning for about 20 minutes. In the stimulation of learning interest, $88 \%$ of the students believe that the BOPPPS model can better stimulate students' interest in learning, while the traditional teaching model is obviously poor in that. We can see that the BOPPPS model plays a very good role in oral Chinese classroom teaching. Both the teaching efficiency and effect are greatly improved after the BOPPPS model is applied.

\subsection{The BOPPPS Model Can Mobilize the Enthusiasm of International Students for Chinese Language Learning and Improve Their Academic Performance}

After the experiment, the passing rate of Chinese proficiency test in the experimental class is significantly higher than that in the control class. From the mastery of knowledge, the integration of professional knowledge, and the acquisition of new knowledge, the BOPPPS model has a better teaching effect, which can be reflected in the final exam results. Class 1 which is taught by traditional teaching methods, the average score of Chinese finals is 70 points. The average grade of class 2 taught by using the BOPPPS model is 85 points, which is significantly higher than the parallel class. What's more, the class performance atmosphere has changed a lot. Most of the students begin to preview the new content and participate in the class activity. The improvement of the students' academic performance has promoted their enthusiasm of learning Chinese.

\subsection{The BOPPPS Model Makes Teachers More Clear About the Teaching Purpose and Requirements}

The teaching model of BOPPPS requires that the teaching process must focus on achieving the goal. The introduction, pre-assessment, participatory learning, post-assessment, summary and other aspects are closely integrated with the teaching process. All steps are closely linked, interacted, and indispensable, prompting the teachers to become clearer about the teaching objectives and requirements. At the same time, the BOPPPS model modularizes the teaching process and emphasizes the importance of the students' participatory learning. This requires teachers to change the original teaching philosophy and always pay attention to the students as the main body to complete the entire teaching process, which is conducive to the improvement of teachers' ability to a certain extent.

\subsection{The BOPPPS Model Makes Students More Clear About Learning Objectives}

In the traditional learning, students often cannot grasp the key points. After the end of a class, most students are in the fog, and they do not know what the real learning focus is. Under the BOPPPS model, the teacher clearly informs the students of the teaching objectives, so that the students know what content they will learn and master in advance. And the students will be more serious and motivated to achieve the best learning effect on the premise of taking the subject as their own.

\section{Reflection on BOPPPS Teaching Model}

The teaching design and application based on BOPPPS model makes the classroom teaching time allocation more 
reasonable. The classroom structure is more effective and complete, and reflects the student-centered education teaching concept (Zhao, Wang, Wang, \& Wang, 2019). At the beginning of the class, the teaching content is introduced in various forms, which fully stimulates students' interest in learning and enables students to enter the state of active learning. In the middle of the class, the learning objectives are introduced in a clear language, so that students know under what circumstances, in what way, what learning tasks need to be completed. In the pre-assessment, various forms of methods are used to reflect the feedback in a convenient, efficient and timely way. According to pre-assessment, teachers use group discussion, case analysis, role-playing, etc. to enable students to deeply participate in the classroom, which improve the concentration of students' learning. In the post-assessment, the teacher can understand the students' mastery of knowledge through simple questions and answers, and test the achievement of students' learning goals in real time. At the end of the class, the teacher will clarify the context of knowledge in a streamlined language, consolidate learning effect, and extend the teaching content for the next lesson.

In the teaching of oral Chinese as a foreign language, the exploration and reform of the BOPPPS teaching model is a useful attempt. It not only mobilizes the enthusiasm and activeness of the students to participate in classroom teaching, but also cultivates the ability and character of students to learn independently. What's more, it also trains students' thinking model while establishing their self-confidence, professional responsibility and sense of accomplishment. The BOPPPS teaching model has greatly improved the quality of teaching Chinese as a foreign language. However, there have been some confusions and problems in the teaching process, which needs further improvement in the follow-up teaching practice.

Firstly, the BOPPPS model has many modules, complex design and high requirements for students. Compared with the traditional teaching model, the BOPPPS model is divided into six modules, each module needs to be strictly designed, and the program is cumbersome. This model has higher requirements for the students' initiative learning. The students need to prepare in advance in order to enter the participatory learning process smoothly. Most of the students do not develop good habits of the preview. This directly lead the teachers to preview with the students during the class, which take up the teaching time to a certain extent, and sometimes break away from the basic concept of the BOPPPS model.

Secondly, the BOPPPS teaching model is more difficult to implement in large class teaching. From the perspective of BOPPPS teaching model, the participatory learning of teacher's and student's interaction is the essence of the whole BOPPPS model. Teachers must design the teaching process around the student-centered teaching concept to promote the achievement of teaching goals and motivate students participate in the teaching process much better to achieve the effectiveness of classroom teaching. Practice shows that the BOPPPS model is more effective in small class teaching, which is conducive to class discussion, group learning, role playing, etc., and the classroom progress is easy to control. However, in the large class such as the "Chinese Culture Introduction" for foreigners, it is relatively difficult for teachers and students to interact between each other, and it is impossible for the teacher to take care of each student.

Thirdly, the BOPPPS teaching model includes many interactive sections, and sometimes students are not really willing to participate. Most students have been taught in the passive teaching model for a long time and do not participate in classroom teaching actively. They are not quite adaptable to the new teaching model of BOPPPS, which hinders the positive progress of classroom teaching, so how to mobilize students' interactive participation is the key to the success of the BOPPPS model in classroom teaching. So it is also the core problem that teachers urgently need to solve.

Finally, the BOPPPS should be an open teaching design model. Teachers should not be constrained by the completeness and order of the six modules in the process of teaching practice. It should be judged appropriately according to the situation and teaching content. It should be easy and efficient, meeting with the students' psychological characteristics and cognitive rules.

\section{Conclusion}

The BOPPPS teaching model is a teacher-oriented, student-centered and practical classroom design model. The experiment shows that the BOPPPS teaching model has changed the boring classroom atmosphere of both the teachers' traditional lectures and students' passive listening in the oral Chinese classroom teaching. This teaching model makes the students become more interested and active in learning, promotes the students' understanding, mastery and application of Chinese knowledge, improves students' self-confidence and sense of accomplishment, stimulates students' interest and enthusiasm for learning, and improves teaching efficiency and effectiveness. We believe that through continuous exploration and practice, the BOPPPS model will play a greater role in teaching reform to improve teaching efficiency quality. 


\section{Acknowledgments}

This work is supported by Ningxia Medical University Education and Teaching Reform Research Project [grant numberNYJY1842].

\section{References}

Cao, D., \& Yin, X. (2016). Canadian BOPPPS Teaching Model and Its Enlightenment to Higher Education Reform. Research and Exploration in Laboratory, 35(2), 196-200.

Chen, G., Zhang, W., \& Wang, P. (2015). Research on Single Chip Microcomputer Teaching Based on BOPPPS and LBD. Journal of Electrical and Electronic Education, 37(5), 65-68.

Liu, H., Zhang, Y., \& Yang, K. (2015). Practice of BOPPPS Model in Operating System Teaching. Computer Education, 19, 83-85

Ministry of Education. (2019). Statistics on studying in China in 2018. Retrieved from http://www.moe.gov.cn/jyb_xwfb/gzdt_gzdt/s5987/201904/t20190412_377692.html

Mu, H., \& Li, C. (2015). BOPPPS Model and Its Application in Research-based Teaching. Shaanxi Education (Higher Education), 10, 27-30.

Niu, Z., \& Lou, Z. ( 2017). Application of BOPPPS Teaching Model in Adult Education Teaching Design. China Adult Education, 16, 97-99.

Shen, L., Guo, Y., \& Zhu, N. (2017). Application of BOPPPS Teaching Model in College English Reversal Class. Course Education Research, 2(20), 123-125.

Wang, H., \& Tian, J. (2018). The Enlightenment of BOPPPS Teaching Model to the Classroom Teaching of New Teachers in Colleges. Education and Teaching Forum, 20, 210-211.

Wang, L., \& Li, S. (2018). Application of BOPPPS Model in Probability Theory and Mathematical Statistics Teaching. Journal of Huainan Vocational and Technical College, 79(18), 70-71.

Wang, Z., Zhou, Y., \& Peng, X. (2016). The Application of BOPPPS Model in the Classroom Teaching of "Signal Analysis and Processing". Computer Engineering and Science, 38(S1), 68-71.

Yan, X., Chen, Y., \& Wang, L. (2016). Effective Teaching design of "University Computer Foundation" based on BOPPPS Model. Heilongjiang Education (Higher Education Research and Appraisal), 8, 36-38.

Zhang, J., \& Zhu, L. (2016). Effective Classroom Teaching Design Based on BOPPPS Model. Vocational and Technical Education, 37(11), 25-28.

Zhao, H., Wang, Y., Wang, Y., \& Wang, B. (2019). The Application of BOPPPS Teaching Model in Physiology Teaching. Basic Medical Education, 21(6), 424-426.

\section{Copyrights}

Copyright for this article is retained by the author(s), with first publication rights granted to the journal.

This is an open-access article distributed under the terms and conditions of the Creative Commons Attribution license (http://creativecommons.org/licenses/by/4.0/). 